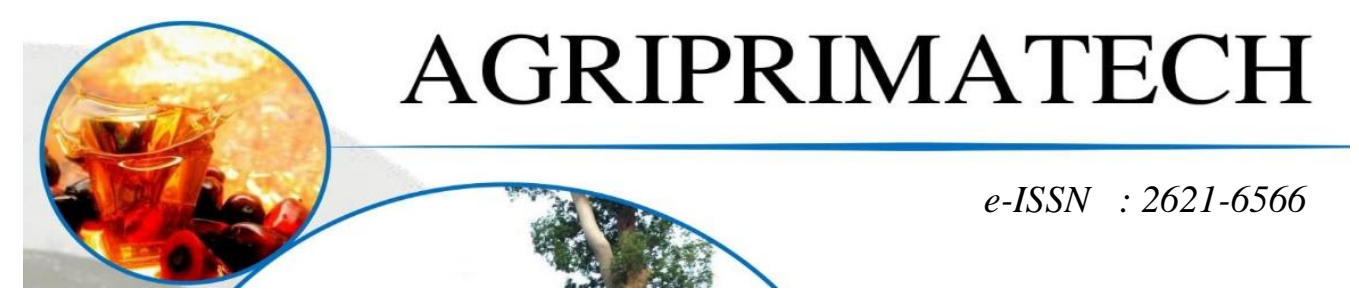

\title{
PERBANDINGAN CURAHAN DAN PRODUKTIVITAS TENAGA KERJA DALAM KELUARGA PADA USAHA TANI LAHAN KERING, LAHAN BASAH DAN PEKERJAAN LAIN DI KECAMATAN PANEI KABUPATEN SIMALUNGUN
}

\author{
J.A MARBUN ${ }^{1}$, MUSTAFA GINTING ${ }^{2}$, DWI TRISNAWATY SITIO ${ }^{3}$ \\ 1,2Dosen Program Studi Agribisnis, Fakultas Pertanian,Universitas Simalungun, Pematangsiantar \\ ${ }^{3}$ Mahasiswa Program Studi, Fakultas Pertanian,Universitas \\ Simalungun,Pematangsiantar, Indonesia \\ Email korespondensi:dwitrisnawaty05@gmail.com
}

\begin{abstract}
Abstrak
Penelitian bertujuan untuk Menganalisis dan membandingkan curahan tenaga kerja dalam keluarga pada usaha tani lahan kering dan usaha tani lahan basah luar usaha tani; Menganalisis dan membandingkan produktivitas tenaga kerja dalam keluarga pada usaha tani lahan kering dan usaha tani lahan basah luar usaha tani; Menganalisis penggunakan surplus tenaga kerja dalam keluarga di luar usaha tani. Penelitian dilaksanakan Penelitian dilaksanakan pada november Juli s/d Desember 2020 dimana daerah penelitian ditentukan secara sengaja (purposive), yaitu di Nagori Sigodang, Rata-rata tenaga kerja dalam keluarga pada lahan ladang adalah 12,24 $\mathrm{HKP} /$ musim dengan rata-rata luas lahan 0,35 rante dan rata-rata tenaga kerja dalam keluarga pada lahan sawah adalah 24,05 HKP/musim dengan rata-rata luas lahan 0,62 HKP, sedangkan pada luar usahatani yaitu sebesar 104,85 HKP/musim tanam; Rata-rata produktivitas tenaga kerja dalam keluarga pada lahan ladang adalah Rp.13.003/HKP, dan lahan sawah adalah Rp.42.407/HKP, sedangkan pada luar usahatani aadalah Rp.60.362/HKP; Potensi TKDK per musim sebanyak 249 HKP. Maka, Surplus sebanyak 121,71 HKP dengan kelebihan TKDK petani mencari pekerjaan lain dengan menjadi buruh tani untuk memaksimalkan TKDL sebanyak 104,85 HKP atau 50,95\%. Dapat kita tarik kesimpulan penggunaan TKDK belum maksimal karena surplus TKDK sebanyak $50,95 \%$, artinya lebih banyak TKDK yang digunakan dari pada menganggur.
\end{abstract}

Kata kunci: Curahan, Produktivitas, Lahan Kering, Lahan Basah

\section{PENDAHULUAN}

Dalam usahatani sebagian besar tenaga kerja berasal dari keluarga petani sendiri yang terdiri atas ayah sebagai kepala keluarga, isteri dan anak - anak petani. Anak - anak berumur 12 tahun misalnya sudah dapat merupkan tenaga kerja yang produktif bagi usahatani. Tenaga kerja yang berasal dari keluarga petani ini merupakan sumbanagan keluarga pada produksi pertanian secara keseluruhan dan tak pernah dinilai dengan uang. Memang usahatani dapat sekali sekali membayar tenaga kerja tambahan. (Tangga et al., n.d. 2011)

Petani dalam usaha taninya tidak selamanya bekerja penuh, karena pada umunya petani akan bekerja penuh pada masa penanaman dan pada masa panen. Misalnya seorang petani menanam jagung, setelah dia menanam jagung dia akan menganggur sembari menunggu jagungnya panen. kondisi inilah yang dinamakan setengah pengangguran 
kentara (visible underemployment) yakni mereka yang bekerja kurang dari jam normal (kurang dari 35 jam/minggu). Petani-petani di Indonesia banyak yang termasuk sebagai setengah pengangguran kentara karena petani yang hanya memiliki lahan yang sempit biasanya bekerja kurang dari 35 jam/minggu dan setengah pengangguran tidak kentara (invisible underemployment) atau pengangguran terselubung (disguised unemployment) yaitu mereka yang produktivitas kerja rendah dan pendapatannya rendah.(Purwantini and Supriyati 2015)

Untuk menambah penghasilan dan memaksimalkan kelebihan potensi tenaga kerja dalam keluarga disinilah petani berusaha mencari pekerjaan tambahan yaitu menjadi buruh tani.Hal ini karena petani kebanyakan tidak memiliki pengetahuaan dan kemampuan lain, untuk mencari pekerjaan lain.(Salim, Susilastuti, and Setyowati 2019)

Kecamatan Panei, Kabupaten Simalungun yang terdiri dari 17 nagori adalah menjadi tempat saya melakukan penelitan. Di Kecamatan Panei lebih banyak kita temui lahan sawah dibandingkan lahan kering, hasil usaha tani yang lebih banyak kita temui yaitu padi dan jagung. Potensi kecamatan panei pada usaha tani baik dari ladang dan sawah, seperti padi sawah, padi gogo, jagung, ubi kayu, dan kacang tanah.

Nagori yang saya pilih untuk penelitan adalah Nagori Sigodang Barat sebagai lahan kering. Saya memilih tempat ini dikarenakan Nagori Sigodang Barat hampir semua penduduk berprofesi sebagai petani dan di nagori ini luas lahan pertanian masih sangat luas dan usaha taninya bervariasi Nagori Sigodang Barat terdiri dari atas 5 dusun, yaitu Kampung Tempel, Dolok Marimbun, Tanjung Mariah, Persatuan Baru Dan Sigodang.

Nagori Janggir Leto sebagai lahan basah, nagori ini sangat luas terbentang persawahan dan jumlah petani masih sangat banyak. Di Nagori ini pertanian sudah lumayan maju. Nagori janggir leto terdiri dari 8 dusun, yaitu Bonbongan,
Sibaganding, Bahkata, Peranginan, Silamaklamak, Tomuan Pane.

Dalam penelitian ini dicari kebenaran atas anggapan bahwa ada perbandingan antara curahan dan produktivitas tenaga kerja dalam keluarga pada usaha tani lahan kering, lahan basah dan luar uaha tani lainnya di kecamatan panei. Peneliti meneliti di dua Nagori yaitu Nagori Sigodang Barat sebagai lahan kering dan Nagori Janggir Leto sebagai lahan basah. Dan dalam penelitian ini secara serentak akan diukur dan diperbandingkan curahan kerja dan produktivitas tenaga kerja dalam keluarga pada usaha tani. Penelitian ini bertujuan untuk Menganalisis danmembandingkan curahan tenaga kerja dalam keluarga pada usaha tani lahan kering dan usaha tani lahan basah luar usaha tani; Menganalisis dan membandingkan produktivitas tenaga kerja dalam keluarga pada usaha tani lahan kering dan usaha tani lahan basah luar usaha tani; Menganalisis penggunakan surplus tenaga kerja dalam keluarga di luar usaha tani.

\section{METODE PENELITIAN}

Penelitian dilaksanakan pada november Juli s/d Desember 2020 dimana daerah penelitian ditentukan secara sengaja (purposive), yaitu di Nagori Sigodang Barat dan Nagori Janggir Leto Kecamatan Panei, Kabupaten Simalungun, dengan mempertimbangkan bahwa di Nagori Sigodang Barat memiliki lahan kering yang luas dan hasil usaha tani yang beragam dan pada Nagori Janggir Leto yang memiliki lahan sawah yang luas.

Dalam penelitian ini populasinya adalah semua petani lahan ladang dan sawah di Nagori Sigodang Barat dan Nagori Janggir Leto.Maka peneliti menentukan besar sampel yaitu, masing masing 30 RT pada kedua nagori (Sigodang Barat dan Janggir Leto) yang memuliki usahatani lahan kering dan lahan sawah penarikan sampel dilakukan secara acak sederhana. 


\section{Metode Pengukuran Variabel}

\section{Curah tenaga kerja}

Indikator Jumlah hari orang kerja, pengukuran jam kerja efektif untuk semua pekerjaan pada lahan basah, lahan kering dan luar usaha tani.

2. Potensi tenaga kerja

Indikatorjumlah anggotakeluarga, umur (16 - 50 tahun) dan (minimal $10-15$ tahun), pengukuran Jam kerja $=7$ jam,Pria Dewasa $=1 \mathrm{HKP}$, Wanita Dewasa $=0,7 \mathrm{HKP}$, Anak - anak $=0,5$ HKP(Kawengian, Mandey, and Waney 2019)

3. Pendapatan usaha tani

Sebelumnya kita harus menghitung (Biaya total : $\mathrm{TC}=\mathrm{VC}+\mathrm{FC}$ ) dan (Penerimaan total : TR $=$ Py. Y). Biaya eksplisit adalah biaya yang benar - benar dikeluarkan oleh rumah tangga untuk menjalankan usahataninya. Contoh: biaya benih, pupuk, upah tenaga kerja luar keluarga, dll. Biaya implisit adalah biaya yang tidak benar benar dikeluarkan oleh rumah tangga untuk menjalankan usahataninya. Contoh: upah tenaga kerja dalam keluarga, sewa tanah sendiri, bunga modal sendiri,dlIDan biaya implisit tidak termasuk pengeluaran). 4. Produktivitas tenaga kerja dalam keluarga

Pengukuran Produktivitas $=$ Penerimaan usahatani /curah tenaga kerja dalam keluarga(Oktaviani.J 2018)

5. Surplus tenaga kerja dalam keluarga

Pengukuran $=$ potensi tenaga kerja tenaga kerja dalam keluarga dan luar keluarga.

\section{Metode Analisis Data}

Untuk menguji curah tenaga kerja maka, langkah pertama adalah dengan menghitung curah tenaga kerja pada ladang dan sawah, kemudian untuk membandingkan curah tenaga kerja pada lahan ladang dan sawah begitu juga dengan menguji hipotesis 2 maka di gunakan rumus sebagai berikut analisi uji t menggunakan SPSS :

$$
t_{\text {hitung }}=\frac{X_{1}-X_{2}}{\sqrt{\frac{\left(n_{A-1}\right) S_{A}{ }^{2}+\left(n_{B-1}\right) S_{B}{ }^{2}}{n_{A}+n_{B}-2} \sqrt{\frac{1}{n_{A}}+\frac{1}{n_{B}}}}}
$$

Keterangan :

$\mathrm{t}=\mathrm{t}$ hitung

$X_{1}=$ Rata - rata curah tenaga kerja lahan kering

$X_{2}=$ Rata - rata curah tenaga kerja lahan basah

$S^{2}{ }_{1}=$ standar deviasi lahan kering

$S^{2}{ }_{2}=$ standar deviasi lahan basah

$n_{A}=$ Banyaknya sampelpetani pada lahan kering

$n_{B}=$ Banyaknya sampel petani pada lahan basah

Untuk mencari varians sampel, maka dgunakan rumus :

$$
S^{2}=\frac{\sum_{i=1}^{n}\left(X_{i}-X\right)}{N-1},
$$

dimana $x$ : rata - rata hitung sampel,

$\mathrm{n}$ : ukuran sampel,

$\mathrm{X}_{1}$ : data ke - $\mathrm{i}$

Nilai a adalah peluang untuk membuat kesalahan tipe I. Kesalahan tipe I adalah kesalahan menolak Ho, padahal Ho benar. Penentuan tingkat signifikansi ini beravariasi sesuai keinginan peneliti. Nilai a yang digunakan adalah $0,05(5 \%)$. Nilai a merupakan batasan dalam menentukan pengambilan keputusan uji hipotesa.

Sedangkan untuk menguji hipotesis 3, maka dilakukan dengan membandingkan curahan tenaga kerja luar keluarga usahatani dengan potensi tenaga kerja dalam keluarga yang tidak digunakan atau menganggur.Dalam penelitain untuk perbandingn digunakan SPSS 2.0.

\section{HASIL dan PEMBAHASAAN}

\section{Karakteristik Responden dan Rumah Tangga Petani}

Petani sampel yang dimaksud disini adalah seluruh petani pada lahan kering dan lahan basah serta di luar usaha tani lainnya. Disini usahatani yang dilakukan petani adalah tanaman semusim, seperti padi, jagung, kacang, cabai dll. Karakteristik peternak sampel 
dalam penelitian ini terdiri dari tingkat pendidikan, tingkat usia, jumlah tangguanga. Berdasarkan wawancara karakteristik sampel di nagri sigodang barat dan janggir leto adalah sebagai berikut:

Tabel 1. Karakteristik Responden dan Rumah Tangga Petani

\begin{tabular}{|c|c|c|c|}
\hline No. & Uraian & Range & Rataan \\
\hline 1. & $\begin{array}{l}\text { Tingkat } \\
\text { pendidikan } \\
\text { (tahun) }\end{array}$ & $6-12$ & 10,2 \\
\hline 2. & $\begin{array}{l}\text { Tingkatusia } \\
\text { (tahun) }\end{array}$ & $10-50$ & 49,0 \\
\hline 3. & $\begin{array}{l}\text { Jumlah } \\
\text { tanggungan } \\
\text { (jiwa) }\end{array}$ & $4-7$ & 5,4 \\
\hline 4. & Lahan ladang & $0,2-0,48$ & 0,35 \\
\hline 5. & Lahan sawah & $0,4-0,68$ & 0,62 \\
\hline
\end{tabular}

Sumber : Data Primer Diolah (2021)

Tingkat pendidikan petani sampel hanya pada tingkat SMA adalah 10,2 dengan range 6-12 tahun. Hal ini menunjukan bahwa tingkat pendidikan yang dimiliki petani cukup tinggi.usia ratarata petani adalah 49,0 dengan range 10 50 tahun.jumlah tanggungan petani ratarata 5,4 dengan range 4-7 orang.

\section{Pencurahan Tenaga Kerja Usahatani}

Tenaga kerja merupakan salah satu faktor penting dalam usahatani karenamerupakan penunjang terhadap berlangsungnya usahatani. Dalam penelitian ini terdapat beberapa kegiatan usahatani yakni: pemilihan benih, persiapan lahan, penanaman, pemupukan, panen, pasca panen. Untuk pencurahan tenaga kerja dapat dilihat pada tabel berikut.

Tabel 2.Rata-rata Pencurahan Tenaga

Kerja Pada Usahatani Sawah dan

Lahan Kering, Desa Sigodang Barat, MT II Tahun 2020

\begin{tabular}{llcccccc}
\hline \multirow{2}{*}{ No } & \multirow{3}{*}{$\begin{array}{c}\text { Jenis } \\
\text { Kegiatan }\end{array}$} & \multicolumn{3}{c}{ Ladang } & \multicolumn{5}{c}{ Sawah } \\
\cline { 3 - 8 } & & & & & & & \\
\cline { 3 - 8 } & & TKDK & TKLK & Jlh & TKDK & TKLK & Jlh \\
\hline 1 & Persiapan & 0 & 7,53 & 7,53 & 5,00 & 11,51 & 16,51 \\
& Lahan & & & & & & \\
2 & Pembibitan & 0 & 0 & 0 & 3,33 & 0 & 3,33 \\
3 & Penanaman & 4,04 & 2,87 & 6,91 & 5,53 & 10,53 & 16,06 \\
4 & Pengendalia & 0,69 & 0 & 0,69 & 4,04 & 7,43 & 11,47 \\
& n OPT & & & & & & \\
5 & Pemupukan & 2,02 & 0 & 2,02 & 4,04 & 0 & 4,04
\end{tabular}

$\begin{array}{lcccccc}\text { Panen } & 4,82 & 2,53 & 7,35 & 1,25 & 39,58 & 40,83 \\ \text { Pasca } & 4,82 & 0 & 4,82 & 4,82 & 0 & 4,82 \\ \text { Panen } & & & & & & \\ \text { Jumlah } & \mathbf{1 6 , 3 9} & \mathbf{1 2 , 9 3} & \mathbf{2 9 , 3 2} & \mathbf{2 8 , 0 1} & \mathbf{6 9 , 0 5} & \mathbf{9 7 , 0 6} \\ \text { Persentase } & \mathbf{5 5} & \mathbf{4 5} & \mathbf{1 0 0} & \mathbf{2 1} & \mathbf{7 1} & \mathbf{1 0 0}\end{array}$

Sumber : Data Primer Diolah (2021)

Pada Tabel didapat jumlah tenaga kerja yang paling banyak di gunakan adalah pada lahan sawah sebanyak 97,06 HKP dibandingkan lahan ladang hanya sebanyak 29,32 HKP. Pada lahan ladang tenaga kerja dalam keluarga digunakan yaitu 4,82 HKP dan pada tenaga kerja luar keluarga sebanyak 7,53 HKP. Penggunaan tenaga kerja pada lahan ladang lebih banyak pada proses persiapan lahan yaitu 7,53 HKP, dengan menggunakan tenaga mesin atau jetor. Sedangkan pada lahan sawah tenaga kerja luar keluarga lebih banyak digunakan yaitu 69,05 HKP dan tenaga kerja dalam keluarga hanya sebanyak 28,01 Penggunaan tenaga kerja paling banyak pada proses panen yaitu 40,83 . Hal lainya yang membuat tenaga kerja luar keluarga lebih banyak karena ada faktor serempak dalam proses penanaman dan panen, sehingga tenaga kerja dalam usahatani harus lebih banyak.

Tabel 3.Rata-rata Pencurahan Tenaga Kerja Pada Usahatani Sawah dan Lahan Kering, Desa Janggir Leto, MT II Tahun 2020

\begin{tabular}{lcccccc}
\hline Jenis Kegiatan & TKDK & $\begin{array}{c}\text { Ladang } \\
\text { TKLK }\end{array}$ & Jlh & TKDK & $\begin{array}{c}\text { Sawah } \\
\text { TKLK }\end{array}$ & Jlh \\
\hline Persiapan & 0 & 7,87 & 7,87 & 3,33 & 16,71 & 20,04 \\
Lahan & & & & & & \\
Pembibitan & 0 & 0 & 0 & 3,00 & 0 & 3,00 \\
Penanaman & 1,97 & 6,00 & 7,97 & 5,60 & 9,40 & 15 \\
Pengendalian & 0,49 & 0 & 0,49 & 1,80 & 10,47 & 12,27 \\
OPT & 1,72 & 0 & 1,72 & 3,23 & 1,20 & 4,43 \\
Pemupukan & 1,97 & 6,07 & 8,40 & 1,31 & 35,74 & 37,05 \\
Panen & 1,97 & 0 & 1,97 & 1,80 & 0 & 1,80 \\
Pasca & & & & & & \\
Panen & & $\mathbf{2 8 , 4 2}$ & $\mathbf{2 0 , 0 7}$ & $\mathbf{7 3 , 5 2}$ & $\mathbf{9 3 , 5 9}$ \\
$\quad$ Jumlah & $\mathbf{8 , 0 7}$ & $\mathbf{1 9 , 9 4}$ & $\mathbf{2 8}$ & $\mathbf{1 0 0}$ \\
Persentase & $\mathbf{3 0}$ & $\mathbf{7 0}$ & $\mathbf{1 0 0}$ & $\mathbf{2 1}$ & $\mathbf{7 9}$ & $\mathbf{1 0 0}$ \\
\hline
\end{tabular}

Data Primer Diolah (2021)

Pada Tabel didapat jumlah tenaga kerja yang paling banyak di gunakan adalah pada lahan sawah sebanyak 93,59 HKP dibandingkan lahan ladang hanya sebanyak 28,42 HKP. Pada lahan ladang tenaga kerja luar keluarga lebih banyak digunakan yaitu 19,94 HKP dan pada 
tenaga kerja dalam keluarga hanya sebanyak 8,07 HKP. Penggunaan tenaga kerja pada lahan ladang lebih banyak pada proses panen yaitu 8,40 HKP. Sedangkan pada lahan sawah tenaga kerja luar keluarga lebih banyak digunakan yaitu 73,52 HKP dan tenaga kerja dalam keluarga hanya sebanyak 20,07 HKP. Penggunaan tenaga kerja paling banyak pada proses panen yaitu 37,05 .

\section{Produksi,Harga,Biaya, Penerimaan, Pendapatan}

Tabel 4. Produksi, Harga, Biaya, Penerimaan, Pendapatan pada lahan ladang(jagung)

\begin{tabular}{clc}
\hline No & \multicolumn{1}{c}{ Uraian } & Rata-rata permusim $(\mathbf{R p} / \mathbf{K g}$ \\
\hline 1 & Hasil produksi $(\mathrm{Kg})$ & $1.933,33$ \\
2 & Harga padi $(\mathrm{Rp})$ & 4.520 \\
& Biaya produksi (Rp) & \\
\hline 3 & Tenaga kerja & 1.821 .930 \\
4 & Sarana & 1.785 .070 \\
5 & Penyusutan alat & 254.330 \\
6 & Sewa lahan & 397,5 \\
& Jumlah biaya (Rp) & \\
\hline 7 & Penerimaan & 8.731 .890 \\
8 & Pendapatan & 4.473 .060 \\
\hline
\end{tabular}

Data Primer Diolah (2021)

PadaTabel menunjukkan bahwa usahatani lahan ladang yaitu yang didapatkan dari hasil rata-rata produksi per usahatani sebesar $1.933 \mathrm{~kg}$, dengan harga jual rata-rata per usahatani sebesar Rp.4.520 sehingga didapatkan rata-rata penerimaan per usahatani sebesar Rp.8.731.893, sehingga telah didapatkan pendapatan usahatani sebesar Rp.4.473.060. Dimana usahatani yang dikerjakan pada lahan ladang adalah usahatani jagung.

Tabel 5. Produksi, Harga, Biaya, Penerimaan, Pendapatan pada lahan sawah

\begin{tabular}{llc}
\hline No & \multicolumn{1}{c}{ Uraian } & Rata-rata permusim $(\mathbf{R p} / \mathbf{K g})$ \\
\hline 1 & Hasil produksi (Kg) & 3.905 \\
2 & Harga padi (Rp) & 4.330 \\
& Biaya produksi (Rp) & \\
\hline 3 & Pupuk & 1.842 .500 \\
4 & Sewa lahan & 775.500 \\
5 & Tenaga kerja & 6.509 .490 \\
6 & Penyusutan alat & 254,33 \\
& Jumlah biaya (Rp) & \\
\hline 7 & Penerimaan & 16.965 .320 \\
8 & Pendapatan & 7.583 .500 \\
\hline
\end{tabular}

Data Primer Diolah (2021)
Pada Tabel menunjukkan bahwa usahatani lahan sawah yaitu yang didapatkan dari hasil rata-rata produksi per usahatani sebesar $3.905 \mathrm{~kg}$, dengan harga jual rata-rata per usahatani sebesar Rp.4.330 sehingga didapatkan rata-rata penerimaan per usahatani sebesar Rp. 16.965.323, sehingga telah didapatkan pendapatan usahatani padi sebesar Rp.7.583.500. dimana usahatani yang dilakukan pada lahan sawah adalah usahatani padi.

\section{Perbandingan curahan Tenaga Kerja Dalam Keluarga}

Tabel 6. Hasil uji beda curahan tenaga kerja dalam keluarga

\begin{tabular}{lll}
\hline $\begin{array}{c}\text { Jenis } \\
\text { Usahatani }\end{array}$ & $\begin{array}{c}\text { Curahan } \\
\text { TKDK }\end{array}$ & \multicolumn{1}{c}{ Uji statistika } \\
\hline Sawah & 24,04 & sawah-ladang: \\
Lahan & 12,24 & $\mathrm{t}_{\text {hitung }}=8,66$ \\
Kering & & sig. $=0,00$ \\
Luar & 93,37 & sawah - luar UT \\
Usahatani & & $\mathrm{t}_{\text {hitung }}=22,17$ \\
& & sig. $=0,000$ \\
& & Ladang - luar UT \\
& & $\mathrm{t}_{\text {hitung }}=18,87$ \\
& & sig. $=0,000$ \\
\hline
\end{tabular}

Data Primer Diolah (2021)

Dari tabel curahan tenaga kerja dalam keluarga pada sawah sebesar 24,04 HKP, ladang 12,24 HKP dan luaar usahatani 93,37 HKP. Sehinggaa kita dapat menyimpulkan dari analisis uji t bahwa perbandingan curah tenaga kerja pada lahan sawah dan ladang dengannilai sig 0,00 lebih kecil dari 0.5 yang artinya terdapat perberdaan yang signifihan. sedangkan pada lahan ladang dan luar usahatani dengan sig 0,000 lebih kecil dari 0,05 dengan hipotesis 1 diterima.

\section{Perbandingan Produktivitas Tenaga Kerja Dalam Keluarga}

Tabel 7.Produktivitas Tenaga Kerja

\begin{tabular}{lll}
\hline No & Uraian & Produktivitas TKDK \\
\hline $\mathbf{1}$ & Lahan sawah & \\
\hline & Produksi(kg) & 164,32 \\
& Tenaga kerja(HKP) & \\
& penerimaan(Rp) & 10,08 \\
& Biaya tenaga kerja(Rp)
\end{tabular}




\begin{tabular}{lll} 
& $\begin{array}{l}\text { Penerimaan (Rp) } \\
\text { Tenaga kerja(HKP) }\end{array}$ & 705,57 \\
2 $\quad$ Lahan ladang & \\
\hline & $\begin{array}{l}\text { Produksi(kg) } \\
\text { Tenaga kerja(HKP) }\end{array}$ & \\
& & \\
& penerimaan(Rp) & 177,02 \\
& Biaya tenaga kerja(Rp) & \\
& Penerimaan (Rp) & 801,41 \\
& Tenaga kerja(HKP) & \\
3. $\quad$ Luar UT & 60.382
\end{tabular}

Sumber: Data Primer Diolah (2021)

Pada Tabel menunjukan bahwah produktivitas tenaga kerja dalam keluarga terendah adalah pada lahan ladang yaitu Rp.13.003/HKP dengan curah tenaga kerja 12,25 HKP dan penerimaan sebesar Rp. 16.965.323, dikarenakan pada lahan sawah proses pengolahan lahan dan TKLK. Sedangkan pada lahan sawah sebesarRp.42.407/HKP dengan curah tenaga kerja 24,05 HKP dan penerimaan Rp.8.731.893, tidak jauh beda juga dengan lahan ladang produktivitas pada proses pengolahan lahan dan panen menggunakan mekanisasi dan TKLK yang besar. Pada luar usahatani.

Tabel 8. Hasil uji beda produktivitas TKDL

\begin{tabular}{|c|c|c|}
\hline $\begin{array}{l}\text { Jenis } \\
\text { Usahatani }\end{array}$ & $\begin{array}{l}\text { Produktivitas } \\
\text { (Rp/HKP) }\end{array}$ & Uji statistika \\
\hline Lahan Sawah & 42.407 & $\begin{array}{l}\text { 1. sawah-ladang: } \\
\mathrm{t}_{\text {hitung }}=1,69\end{array}$ \\
\hline Lahan ladang & 13.003 & $\begin{array}{l}\text { sig. }=0,000 \\
\text { 2. sawah - luar UT }\end{array}$ \\
\hline $\begin{array}{l}\text { Luar } \\
\text { Usahatani }\end{array}$ & 67.781 & $\begin{array}{l}\text { hitung }=51,93 \\
\text {;ig. }=0,000 \\
\text { 3. Ladang }- \text { luar UT } \\
\text { hitung }=552,04 \\
\text {;ig. }=0,000\end{array}$ \\
\hline
\end{tabular}

Data Primer Diolah (2021)

Dari Tabel rata-rata curahan tenaga kerja dalam keluarga pada sawah sebesar RP.42.407/HKP, ladang Rp.13.003/HKP dan luar usahatani Rp.60.382/HKP.Sehinggaa kita dapat menyimpulkan dari analisis uji t bahwa perbandingan produktivitas pada lahan sawah dan ladang dengan nilai sig 0,000 lebih kecil dari 0.05 yang artinya tidak terdapat perberdaan yang signifikan. Pada lahan sawah dan luar usahatani dengan nilai sig 0,000 lebih kecil dari 0,05 yang artinya terdapat perberdaan yang sangat signifikan, sedangkan pada lahan ladang dan luar usahatani dengan sig 0,000 lebih kecil dari 0,05 yang artinya terdapat perberdaan yang sangat signifikan Hipotesis 2 diterima diterima.

\section{Surpus tenaga kerja}

Tabel 9. Surplus tenaga kerja dalam keluarga

\begin{tabular}{|c|c|c|}
\hline No & Uraian & Jumlah HKP \\
\hline 1 & Potensi TKDK & 249 \\
\hline 2 & $\begin{array}{l}\text { Penggunaan } \\
\text { lahan ladang }\end{array}$ & 12,25 \\
\hline 3 & $\begin{array}{l}\text { Penggunaan } \\
\text { lahan sawah }\end{array}$ & 24,05 \\
\hline 4 & Surplus tenaga kerja & 212,71 \\
\hline 4 & $\begin{array}{l}\text { Penggunaan } \\
\text { luar UT }\end{array}$ & 104,85 \\
\hline 6 & Menganggur & 107,86 \\
\hline
\end{tabular}

Data Primer Diolah (2021)

Pada Tabel dapat kita ketahui ratarata potensi TKDK sebanyak 2,49 $\mathrm{HKP} /$ hari. Sehingga untuk menggetahui potensi TKDK per musim, maka potensi TKDK dikalikan dengan jumlah hari kerja selama 4 bulan, yaitu 100 hari. Maka didapat potensi TKDK per musim sebanyak 249 HKP.

Sehingga, Surplus sebanyak 212,71 HKP dengan kelebihan TKDK petani mencari pekerjaan lain dengan menjadi buruh tani untuk memaksimalkan TKDL sebanyak 104,85 HKP atau 50,95\%.

Dapat kita tarik kesimpulan penggunaan TKDK belum maksimal karena surplus TKDK sebanyak 50,95\%, artinya lebih banyak TKDK yang mengganggur dari pada bekerja hipotesis 3 diterima.

\section{Pembahasan}

Rata-rata tenaga kerja dalam keluarga pada lahan ladang adalah 12,24 $\mathrm{HKP} /$ musim dengan rata-rata luas lahan $0,35 \mathrm{ha}$ dan rata-rata tenaga kerja dalam keluarga pada lahan sawah adalah $24,05 \mathrm{HKP} /$ musim dengan rata-rata luas lahan $0,62 \mathrm{ha}$, sedangkan pada luar usahatani yaitu sebesar 93,36 HKP/musim tanam. Dimana tenaga kerja paling banyak 
digunakan adalah pada luar usaha tani dengan menjadi buruh tani. Diwaktu luang atau setelah siap melakukan pekerjaan diladang/sawah masing-masing, disinilah petani mempunyai peluang menjadi buruh tani. Petani menjadi buruh tani menjadi juga salah satunya untuk memenuhi kehidupan sehari-hari.sehingga jika dijumlah tenaga kerja dalam keluarga pada lahan ladang, sawah dan luar usahatanimenjadi $\quad 121,77 \mathrm{HKP} /$ musim tanim.

Rata-rata pendapatan pada lahan ladang adalah Rp.4.473.000/musim tanam, dengan rata-rata luas lahan 0,35ha. Rata-rata pada lahan sawah Rp.7.583.500/musim tanam, dengan ratarata luas lahan 0,62ha. Pada luar usahatani rata-rata pendapatan Rp.6.329.000/musim tanam dengan ratarata jumlah anggota keluarga 5,4 orang. Dimana pendapatan paling besar diperoleh pada lahan sawah, akan tetapi perbedaan pendapatan diatas tidak terlalu siignifikan.

Rata-rata produktivitas tenaga kerja dalam keluarga pada lahan ladang adalah Rp.13.003/HKP, dan lahan sawah adalah Rp.42.407/HKP, sedangkan pada luar usahatani aadalah Rp.60.362/HKP. Nilai produktivitas paling tinggi adalah pada lahan sawah, karena pada lahan sawah penggunaan tenaga kerja dalam keluarga sangat sedikit dikarenakan penggunaan mekanisasi pada lahan sawah sadah banyak, yaitu pada proses persiapan lahan dan panen.

Potensi TKDK per musim sebanyak 249 HKP. Maka, Surplus sebanyak 121,71 HKP dengan kelebihan TKDK petani mencari pekerjaan lain dengan menjadi buruh tani untuk memaksimalkan TKDL sebanyak 104,85 HKP atau 50,95\%. Dapat kita tarik kesimpulan penggunaan TKDK belum maksimal karena surplus TKDK sebanyak $50,95 \%$, artinya lebih banyak TKDK yang digunakan dari pada menganggur hipotesis 3 diterima.

\section{KESIMPULAN}

1. Rata-rata tenaga kerja dalam keluarga pada lahan ladang adalah 12,24 $\mathrm{HKP} /$ musim dengan rata-rata luas lahan 0,35 ha dan rata-rata tenaga kerja dalam keluarga pada lahan sawah adalah 24,05 HKP/musim dengan ratarata luas lahan 0,62 ha, sedangkan pada luar usahatani yaitu sebesar 104,85 HKP/musim tanam.

2. Rata-rata produktivitas tenaga kerja dalam keluarga pada lahan ladang adalah Rp.13.003/HKP, dan lahan sawah adalah Rp.42.407/HKP, sedangkan pada luar usahatani aadalah Rp.60.362/HKP.

3. Potensi TKDK per musim sebanyak 249 HKP. Maka, Surplus sebanyak 121,71 HKP dengan kelebihan TKDK petani mencari pekerjaan lain dengan menjadi buruh tani untuk memaksimalkan TKDL sebanyak 104,85 HKP atau 50,95\%. Dapat kita tarik kesimpulan penggunaan TKDK belum maksimal karena surplus TKDK sebanyak $50,95 \%$, artinya lebih banyak TKDK yang digunakan dari pada menganggur.

\section{DAFTAR PUSTAKA}

Kawengian, Trifly, Juliana Ruth Mandey, and Nordy Fritsgerald Lucky Waney. 2019. "Curahan Tenaga Kerja Pada Usahatani Padi Di Desa Lowian Kecamatan Maesaan." AgriSosioekonomi 15(3):397. doi: 10.35791/agrsosek.15.3.2019.25772

Oktaviani.J. 2018. "Pengaruh Tenaga Kerja, Teknologi Dan Modal Dalam Meningkatkan Produksi Di Indrustri Pengelolahan Garam." Sereal Untuk 51(1):51.

Purwantini, Tri Bastuti, and Supriyati. 2015. "Dinamika Produktivitas Tenaga Kerja Perdesaan: Komparasi Antar Agroekosistem." Panel Petani Nasional: Mobilisasi Sumber Daya 
Agriprimatech

Vol. 5 No. 1, Oktober 2021

e-ISSN :2621-6566

Dan Penguatan Kelembagaan

Pertanian 261-81.

Salim, M. Noor, Darwati Susilastuti, and Rini Setyowati. 2019. "Analisis

Produktivitas Penggunaan Tenaga

Kerja Pada Usahatani Kentang."

Jurnal IImu Pertanian 12(1):1-16.

Tangga, Rumah, Petani Pedesaan, D. A.

N. Perkotaan, and Suatu Kasus. n.d.

“5505-9041-2-Pb." 251-62. 